\title{
Interim 2019/20 influenza vaccine effectiveness: six European studies, September 2019 to January 2020
}

Angela Rose ${ }^{1,2}$, Esther Kissling, ${ }^{1,2}$, Hanne-Dorthe Emborg ${ }^{3}$, Amparo Larrauri ${ }^{4}$, Jim McMenamin ${ }^{5}$, Francisco Pozo ${ }^{6}$, Ramona

Trebbien $^{7}$, Clara Mazagatos ${ }^{4}$, Heather Whitaker ${ }^{8}$, Marta Valenciano ${ }^{1}$, European IVE group ${ }^{9}$

1. Epiconcept, Paris, France

2. Authors contributed equally to the study and manuscript writing

3. Department of Infectious Disease Epidemiology and Prevention, Statens Serum Institut, Copenhagen, Denmark

4. National Epidemiology Centre, Institute of Health Carlos III, Madrid, Spain; CIBER de Epidemiología y Salud Pública (CIBERESP), Institute of Health Carlos III, Madrid, Spain

5. Health Protection Scotland, Glasgow, United Kingdom

6. National Centre for Microbiology, National Influenza Reference Laboratory, WHO-National Influenza Centre, Institute of Health Carlos III, Madrid, Spain; CIBER de Epidemiología y Salud Pública (CIBERESP), Institute of Health Carlos III, Madrid, Spain

7. Department of Virus and Microbiological Special diagnostics, National Influenza Center, Statens Serum Institut, Copenhagen, Denmark

8. Public Health England, London, United Kingdom

9. European Influenza Vaccine Effectiveness (IVE) group members are listed at the end of the article.

Correspondence: Angela Rose (a.rose@epiconcept.fr)

Citation style for this article:

Rose Angela, Kissling Esther, Emborg Hanne-Dorthe , Larrauri Amparo, McMenamin Jim, Pozo Francisco, Trebbien Ramona, Mazagatos Clara, Whitaker Heathe , Valenciano Marta, European IVE group . Interim 2019/20 influenza vaccine effectiveness: six European studies, September 2019 to January 2020. Euro Surveill. 2020;25(10): $\mathrm{pii}=2000153$. https://doi.org/10.2807/1560-7917.ES.2020.25.10.2000153

Article submitted on 18 Feb 2020 / accepted on 05 Mar 2020 / published on 12 Mar 2020

Background: Influenza $\mathrm{A}\left(\mathrm{H}_{1} \mathrm{~N}_{1}\right)$ pdmo9, $\mathrm{A}\left(\mathrm{H}_{3} \mathrm{~N}_{2}\right)$ and $B$ viruses were co-circulating in Europe between September 2019 and January 2020. Aim: To provide interim 2019/20 influenza vaccine effectiveness (VE) estimates from six European studies, covering 10 countries and both primary care and hospital settings. Methods: All studies used the test-negative design, although there were some differences in other study characteristics, e.g. patient selection, data sources, case definitions and included age groups. Overall and influenza (sub)type-specific VE was estimated for each study using logistic regression adjusted for potential confounders. Results: There were 31,537 patients recruited across the six studies, of which 5,300 (17\%) were cases with 5,310 infections. Most of these $(4,466$; $84 \%$ ) were influenza A. The VE point estimates for all ages were $29 \%$ to $61 \%$ against any influenza in the primary care setting and $35 \%$ to $60 \%$ in hospitalised older adults (aged 65 years and over). The VE point estimates against $\mathrm{A}\left(\mathrm{H}_{1} \mathrm{~N}_{1}\right)$ pdmog (all ages, both settings) was $48 \%$ to $75 \%$, and against $\mathrm{A}\left(\mathrm{H}_{3} \mathrm{~N}_{2}\right)$ ranged from $-58 \%$ to $57 \%$ (primary care) and $-16 \%$ to $60 \%$ (hospital). Against influenza B, VE for all ages was $62 \%$ to $83 \%$ (primary care only). Conclusions: Influenza vaccination is of continued benefit during the ongoing 2019/20 influenza season. Robust end-of-season VE estimates and genetic virus characterisation results may help understand the variability in influenza (sub) type-specific results across studies.

\section{Introduction}

All European Union (EU) countries and the United Kingdom (UK) recommend seasonal influenza vaccine for older adults and those at increased risk of influenza complications and severe disease, as well as for patients with chronic conditions [1]. In addition, universal childhood influenza is available in some countries in the World Health Organization (WHO) European Region, and was introduced incrementally in the UK in 2013/14 [2].

The 2019/20 northern hemisphere influenza season WHO trivalent influenza vaccine strains recommendations were for an A/Brisbane/02/2018 ( $\left.\mathrm{H}_{1} \mathrm{~N}_{1}\right)$ pdmo9like virus, an $\mathrm{A} / \mathrm{Kansas} / 14 / 2017\left(\mathrm{H}_{3} \mathrm{~N}_{2}\right)$-like virus and a $\mathrm{B} /$ Colorado/06/2017-like virus (B/Victoria lineage) [3]. Quadrivalent vaccines were recommended to also include a B/Phuket/3073/2013-like virus (B/Yamagata lineage) [4].

The 2019/20 influenza season started early in most countries of the WHO European Region, with influenza $A\left(\mathrm{H}_{1} \mathrm{~N}_{1}\right)$ pdmog and $\mathrm{A}\left(\mathrm{H}_{3} \mathrm{~N}_{2}\right)$ virus subtypes, as well as influenza $B$ circulating throughout the region, although predominantly influenza A overall (69\%) [5]. Despite this, some countries reported dominance of influenza $B$, with a few reporting co-dominance [5].

The I-MOVE (Influenza - Monitoring Vaccine Effectiveness in Europe) network has measured influenza vaccine effectiveness (VE) annually since 2008/09, with its partners including Denmark, Spain, 
Countries providing interim influenza vaccine effectiveness results, influenza season 2019/20 $(n=10)$

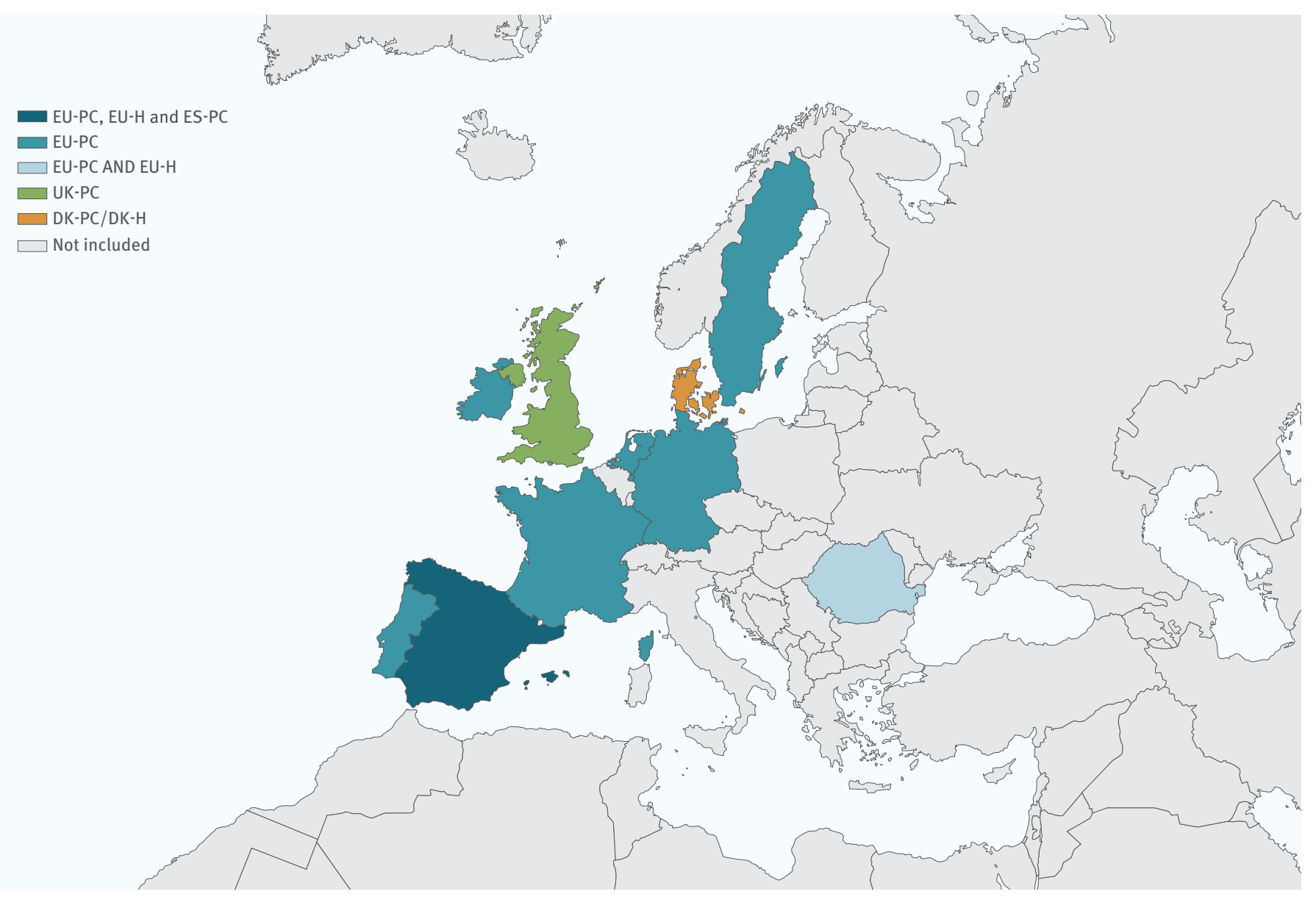

DK-PC/DK-H: Denmark primary care and hospital studies; ES-PC: Spain primary care study; EU-H: European Union hospital-based multi-country I-MOVE study; EU-PC: European Union primary care-based multi-country I-MOVEstudy; I-MOVE: Influenza - Monitoring Vaccine Effectiveness in Europe; UK-PC: United Kingdom primary care study.

the UK and many EU countries measuring VE through the I-MOVE multicentre studies. We summarise interim influenza VE estimates for the 2019 /20 season from six studies (four single-country and two multi-country), with out- and in-patient (hospital) settings, in order to provide information for measures of influenza prevention and control for the remaining season. Results presented here also helped to inform the February 2020 WHO Vaccine Strain Selection Committee.

\section{Methods}

\section{Study setting}

The four primary care $(P C)$ studies were conducted in Denmark (DK-PC), Spain (ES-PC), the UK (UK-PC) and through the EU I-MOVE multi-country network (EU-PC; eight of nine participating countries in this network having available data for interim analysis). The two hospital setting $(\mathrm{H})$ studies were in Denmark (DK-H) and through the EU I-MOVE multi-country network (EU-H; two of 11 participating countries in this network having available data for interim analysis) (Figure 1). In total,
10 countries contributed data to the interim influenza vaccine effectiveness results presented in this article.

\section{Study design}

The methods for all six studies have already been described [6-10]. The test-negative design [11] was used in all studies, although some studies varied in their patient selection and/or data collection (Table 1). Briefly, patients presenting to participating primary care settings with symptoms of influenza-like illness (ILI) or acute respiratory infection (ARI) were swabbed. For the hospital setting swabs were taken from those with symptoms of severe ARI (SARI). Three studies used an exhaustive or systematic selection of patients to swab (EU-H, ES-PC and EU-PC), while physicians' discretion was used to select patients for swabbing in the others (DK-H, DK-PC and UK-PC). Samples were tested by reverse transcription (RT)-PCR for generic influenza virus detection, type $A$ subtyping and type $B$ lineage determination. Cases were defined as patients with positive results by influenza virus (sub)type. Controls were defined as those with negative results. 
Vaccinated patients were defined as those having had the 2019/20 influenza vaccine at least 14 days before onset of symptoms (15 days for two studies: EU-PC and EU-H). Those vaccinated less than 14 days (less than 15 days for two studies) before symptom onset, or with unknown date of vaccination were excluded.

Most study countries (six from EU-PC and Denmark) selected all or a random sample of influenza virus-positive specimens for haemagglutinin genome segment and/or whole genome sequencing. This was followed by phylogenetic analysis to determine clade distribution for potential impact on VE. In Spain, the ES-PC study (regions not included in EU-PC) sequenced an ad hoc sample of influenza viruses. In UK-PC, sequencing is done by two contributing surveillance schemes. One of these sequences all influenza viruses with sufficient genetic material (Ct value 31) and all viruses derived from vaccinated cases. The other one sequences a subset only. Sequencing results were provided for both studies in Denmark together (DK-PC and DK-H).

\section{Ethical statement}

The planning, conduct and reporting of the studies was in line with the Declaration of Helsinki [12]. Official ethical approval and patient consent was not required for DK-H and DK-PC according to Danish regulations, nor for EU-PC (the Netherlands and Spain) and UK-PC, as these studies were classified as being part of routine care/surveillance. Other study sites obtained local ethical approval from a national review board, according to local site regulations, as follows: EU-H (Aragon: approved 20 November 2019 by the CEIC Aragon, no registration number given; Granada: approved 11 October 2019 by the CEIM/CEI Provincial de Granada, no registration number given; Navarra: 2018/95; Romania: CE353/30.09.2019); EU-PC (France: 471393; Germany: EA2/126/11; Ireland: ICGP2019.4.04; Portugal: approved 18 January 2012 by the Ethics Committee of Instituto Nacional de Saúde Doutor Ricardo Jorge, no registration number given; Romania: CE354/30.09.2019; Sweden: 2006/1040-31/2).

\section{Statistical analysis}

Each study computed VE by subtracting the ratio of the odds of vaccination in cases and controls from one, as a percentage $(\mathrm{VE}=(1-$ odds ratio $(\mathrm{OR}) \times 100 \%)$. All studies applied logistic regression to adjust their VE for measured confounding variables (Table 1). Studyspecific VE was estimated overall and where possible, by age group and target population (as defined locally in the various studies and study sites) against influenza A overall, $A\left(\mathrm{H}_{1} \mathrm{~N}_{1}\right)$ pdmog, $A\left(\mathrm{H}_{3} \mathrm{~N}_{2}\right)$, influenza $B$ and $B /$ Victoria. For analyses with a small sample size, defined as those having fewer than 10 cases or controls per parameter, a sensitivity analysis was performed using Firth's method of penalised logistic regression (PLR) to assess small sample bias [13,14]. We considered a difference of $>10 \%$ between the PLR and original estimate to be an indication of small sample bias, and any such estimates were not included.

\section{Results}

From 30 September 2019 to 29 January 2020, in the primary care setting, there were 12,842 patients included in the DK-PC study (1,723 cases), 1,798 in ES-PC (955 cases), 2,987 in EU-PC (1,052 cases) and 2,548 in UK-PC (782 cases). In the hospital setting, there were 10,761 in DK-H (659 cases) and 601 in EU-H (129 cases).

Overall, $84 \%(4,466 / 5,310)$ of confirmed infections were influenza A virus-positive and 16\% $(844 / 5,310)$ were influenza B virus-positive, noting that the previously mentioned total refers to patients rather than infections. The proportion of subtyped influenza $A$ viruses was $93 \%$ to $98 \%$ in EU-H, ES-PC, EU-PC and UK-PC, and $45 \%$ to $51 \%$ in DK-H/DK-PC. Most subtyped influenza $A$ viruses were influenza $A\left(\mathrm{H}_{1} \mathrm{~N}_{1}\right)$ pdmog (67-89\%) in ES-PC, EU-PC and EU-H; this subtype comprised $46 \%$ to $47 \%$ in DK-PC/DK-H and $7 \%$ in UK-PC (Figure 2). The proportion of influenza $B$ viruses ranged from $4 \%$ in UK-PC to $30 \%$ in ES-PC (Figure 2). The proportion of B viruses ascribed to a lineage was $27 \%$ overall $(100 \%$ for EU-H, 70\% for EU-PC, 23\% for UK; lineage information not available in DK-PC, DK-H and ES-PC studies). Most of those that were ascribed to a lineage were $\mathrm{B} /$ Victoria: $98 \%$ in EU-PC, $75 \%$ in UK and $67 \%$ in EU-H.

\section{All influenza (A and B)}

\section{Primary care settings}

For all ages, VE against laboratory-confirmed influenza (both A and B combined) ranged from 29\% (95\% confidence interval $(\mathrm{Cl}): 4$ to 48$)$ in UK-PC to $61 \%(95 \% \mathrm{Cl}$ : 37 to 76 ) in ES-PC. The VE against all influenza among children aged o to 17 years was $64 \%$ (95\% Cl: 16 to 85 ) in EU-PC and 95\% (95\% Cl: 67 to 99) in DK-PC. For those aged o to 14 years in ES-PC, VE was $67 \%(95 \% \mathrm{Cl}: 18$ to 87 ), while for those aged 2 to 17 years in UK-PC, VE was $37 \%$ ( $95 \% \mathrm{Cl}:-21$ to 67 ). For patients aged 18 to 64 years, VE ranged from $36 \%(95 \% \mathrm{Cl}: 1$ to 58$)$ in UK-PC to $58 \%$ (95\% Cl: 43 to 69 ) in DK-PC. For those aged 15 to 64 years in ES-PC, VE was 55\% (95\% Cl: 10 to 77) (Table 2). In ES-PC and EU-PC target groups for influenza vaccination, VE was 60\% (95\% Cl: 22 to 79$)$ and 53\% (95\% $\mathrm{Cl}: 26$ to 70 ), respectively.

\section{Hospital settings}

For all ages, VE against all laboratory-confirmed hospitalised influenza was $40 \%$ in DK-H (95\% Cl: 27 to 51 ). In older adults (aged at least 65 years), VE was 35\% (95\% Cl: 17 to 49 ) in DK-H and $60 \%$ (95\% Cl: 39 to 74$)$ in EU-H.

\section{Influenza A overall}

Primary care settings

The VE against laboratory-confirmed influenza A for all ages ranged from $30 \%$ (95\% Cl: 4 to 49 ) in UK-PC to $60 \%(95 \% \mathrm{Cl}: 34$ to 76$)$ in ES-PC. The VE against influenza A among adults under 65 years ranged from 38\% (95\% Cl: 3 to 60 ) in UK-PC (18-64-year-olds) to $62 \%$ ( $95 \% \mathrm{Cl}: 20$ to 82 ) in the ES-PC study (15-64-year-olds). 
TABLE 1

Summary of methods for the six European interim influenza vaccine effectiveness studies, influenza season $2019 / 20$ $(\mathrm{n}=31,537)$

\begin{tabular}{|c|c|c|c|c|c|c|}
\hline \multirow{2}{*}{$\begin{array}{l}\text { Study } \\
\text { characteristics }\end{array}$} & \multicolumn{6}{|c|}{ Study } \\
\hline & DK-PC & ES-PC & EU-PC & UK-PC & DK-H & EU-H \\
\hline Study period & $\begin{array}{c}1 \text { October } \\
2019-29 \text { January } \\
2020\end{array}$ & $\begin{array}{c}28 \text { October } \\
2019-26 \text { January } \\
2020\end{array}$ & $\begin{array}{c}30 \text { September } 2019-25 \\
\text { January } 2020\end{array}$ & $\begin{array}{c}1 \text { October } 2019-12 \\
\text { January } 2020\end{array}$ & $\begin{array}{c}1 \text { October } 2019-29 \\
\text { January } 2020\end{array}$ & $\begin{array}{c}2 \text { December } 2019-26 \\
\text { January } 2020\end{array}$ \\
\hline Setting & Primary care & Primary care & Primary care & Primary care & Hospital & Hospital \\
\hline Location & Denmark & $\begin{array}{l}\text { Spain: Sentinel } \\
\text { networks in } 16 \\
\text { of } 19 \text { regions }\end{array}$ & $\begin{array}{c}\text { France, Germany, } \\
\text { Ireland, the Netherlands, } \\
\text { Portugal, Romania, Spain } \\
\text { and Sweden }\end{array}$ & $\begin{array}{c}\text { England, Scotland, } \\
\text { Northern Ireland and } \\
\text { Wales }\end{array}$ & Denmark & $\begin{array}{l}\text { Spain: six hospitals in } \\
\text { three regions; Romania: } \\
\text { three hospitals }\end{array}$ \\
\hline Study design & TND & TND & TND & TND & TND & TND \\
\hline Data source & $\begin{array}{l}\text { Data linkage } \\
\text { of Danish } \\
\text { Microbiology } \\
\text { Database, } \\
\text { the Danish } \\
\text { Vaccination } \\
\text { Register and the } \\
\text { Danish National } \\
\text { Discharge } \\
\text { Register }\end{array}$ & $\begin{array}{l}\text { Sentinel } \\
\text { physicians and } \\
\text { laboratory }^{\mathrm{a}}\end{array}$ & $\begin{array}{l}\text { Sentinel physicians and } \\
\text { laboratory }^{\mathrm{a}}\end{array}$ & $\begin{array}{l}\text { Sentinel physicians } \\
\text { and laboratory }\end{array}$ & $\begin{array}{c}\text { Data linkage of } \\
\text { Danish Microbiology } \\
\text { Database, the Danish } \\
\text { Vaccination Register } \\
\text { and the Danish } \\
\text { National Discharge } \\
\text { Register }\end{array}$ & $\begin{array}{l}\text { Hospital charts, vaccine } \\
\text { registers, interviews } \\
\text { with GPs, laboratory }\end{array}$ \\
\hline $\begin{array}{l}\text { Age groups of } \\
\text { study population }\end{array}$ & $\geq 6$ months & $\geq 6$ months & All ages ${ }^{b}$ & All ages & $\geq 6$ months & $\geq 65$ years \\
\hline Case definition & $\begin{array}{l}\text { Sudden onset of } \\
\text { symptoms with } \\
\text { fever, myalgia } \\
\text { and respiratory } \\
\text { symptoms }\end{array}$ & $\mathrm{EU} \mathrm{ILI}^{\mathrm{c}}$ & $\mathrm{EU} \mathrm{ILI}^{\mathrm{c}}$ & $\begin{array}{l}\text { ILI: Patient presenting } \\
\text { in primary care with } \\
\text { an acute respiratory } \\
\text { illness with physician } \\
\text { diagnosed fever, and } \\
\text { with onset in the } \\
\text { previous } 7 \text { days }\end{array}$ & $\begin{array}{l}\text { ARI: Sudden onset } \\
\text { of symptoms with } \\
\text { fever, myalgia and } \\
\text { respiratory symptoms } \\
\text { among hospitalised } \\
\text { patients }\end{array}$ & EU SARI ${ }^{d}$ \\
\hline $\begin{array}{l}\text { Selection of } \\
\text { patients }\end{array}$ & $\begin{array}{c}\text { At physician's } \\
\text { judgement }\end{array}$ & Systematic & Systematic & $\begin{array}{c}\text { At physician's } \\
\text { judgement }\end{array}$ & $\begin{array}{c}\text { At physician's } \\
\text { judgement }\end{array}$ & Exhaustive \\
\hline $\begin{array}{l}\text { Vaccine types } \\
\text { used nationally or } \\
\text { in the study }{ }^{\mathrm{e}, \mathrm{f}}\end{array}$ & $\begin{array}{l}\text { In the study: } \\
99.5 \% \text { QIV, } 0.5 \% \\
\text { cell-propagated } \\
\text { QIV }\end{array}$ & $\begin{array}{l}\text { In Spain: } 81.8 \% \\
\text { TIV, } 10.3 \% \text { QIV } \\
\text { and } 7.8 \% \text { cell- } \\
\text { propagated QIV }\end{array}$ & $\begin{array}{c}\text { In the study among } \\
\text { controls: } \\
\text { 5\% TIV; } 2 \% \text { adjuvanted } \\
\text { TIV; } 53 \% \text { QIV; } 1 \% \text { LAIV4; } \\
\text { O\% cell-propagated QIV } \\
\text { (one person vaccinated } \\
\text { among controls), } 38 \% \\
\text { unknown }\end{array}$ & $\begin{array}{l}\text { In the study among } \\
\text { controls }: 7 \% \text { LAIV4; } \\
\text { 12\% cell-propagated } \\
\text { QIV, } 14 \% \text { QIV, } 22 \% \\
\text { adjuvanted TIV; } 44 \% \\
\text { unknown }\end{array}$ & $\begin{array}{l}\text { In the study: } 99.5 \% \\
\text { QIV, } 0.5 \% \text { cell- } \\
\text { propagated QIV }\end{array}$ & $\begin{array}{l}\text { In the study among } \\
\text { controls: } 100 \% \text { TIV; } \\
22 \% \text { adjuvanted TIV; } \\
1 \% \text { unknown whether } \\
\text { adjuvanted }\end{array}$ \\
\hline $\begin{array}{l}\text { Variables of } \\
\text { adjustment }\end{array}$ & $\begin{array}{l}\text { Age group, } \\
\text { sex, presence } \\
\text { of chronic } \\
\text { conditions, } \\
\text { calendar time as } \\
\text { month (Oct-Jan) }\end{array}$ & $\begin{array}{l}\text { Age (modelled } \\
\text { as RCS or age } \\
\text { group depending } \\
\text { on analysis), } \\
\text { sex, presence } \\
\text { of chronic } \\
\text { conditions, } \\
\text { onset date } \\
\text { (RCS), region }\end{array}$ & $\begin{array}{l}\text { Age (modelled as RCS, } \\
\text { age group or linear } \\
\text { term depending on } \\
\text { analysis), sex, presence } \\
\text { of any chronic condition } \\
\text { associated with } \\
\text { influenza vaccination } \\
\text { recommendation, onset } \\
\text { date (RCS) and study site }\end{array}$ & $\begin{array}{l}\text { Age group, sex, } \\
\text { month of onset, } \\
\text { surveillance scheme, } \\
\text { risk group }\end{array}$ & $\begin{array}{c}\text { Age group, sex, } \\
\text { presence of chronic } \\
\text { conditions, calendar } \\
\text { time as month (Oct-Jan) }\end{array}$ & $\begin{array}{l}\text { Age (modelled as } \\
\text { RCS or linear term } \\
\text { depending on analysis), } \\
\text { sex, presence of any } \\
\text { chronic condition } \\
\text { associated with } \\
\text { influenza vaccination } \\
\text { recommendation, onset } \\
\text { date (RCS or onset } \\
\text { month depending on } \\
\text { analysis) and study site }\end{array}$ \\
\hline
\end{tabular}

ARI: acute respiratory infection; DK-H: Denmark hospital study; DK-PC: Denmark primary care study; ES-PC: Spain primary care study; EU: European Union; EU-H: EU hospital multicentre I-MOVE study; EU-PC: EU primary care multicentre I-MOVEstudy; GP: general practitioner; ILI: influenza-like illness; I-MOVE: Influenza - Monitoring Vaccine Effectiveness in Europe; LAIV4: quadrivalent live attenuated influenza vaccine; LRI: lower respiratory infection; QIV: quadrivalent inactivated influenza vaccine; RCS: restricted cubic spline; SARI: severe acute respiratory infection; TIV: trivalent inactivated influenza vaccine; TND: testnegative design; UK-PC: United Kingdom primary care study.

a 235 of 813 sentinel physicians included in ES-PC were also included in EU-PC.

b Patients $<6$ months should have been excluded from the study, however the age group is specified as 'all ages' as age in months could not be verified from the data.

c EU ILI: Sudden onset of symptoms AND at least one of the following four systemic symptoms: fever or feverishness, malaise, headache, myalgia AND at least one of the following three respiratory symptoms: cough, sore throat, shortness of breath.

${ }^{d}$ EU SARI: Hospitalised person with one or more of: fever/feverishness, malaise, headache, myalgia, deterioration of general condition (asthenia, weight loss, anorexia, confusion/dizziness) AND one or more respiratory symptom (cough, sore throat or shortness of breath) at admission or within 48 hours.

e Vaccines were prepared from egg-propagated vaccine viruses, non-adjuvanted and administered intramuscularly unless otherwise specified.

${ }^{f}$ Where indicated, vaccine coverage among controls were used as representative of the source population from which the cases arose.

g UK vaccine strategy: 2-17 years of age: LAIV4 or QIV; 18-64 years of age: QIV or cell-propagated QIV; $\geq 65$ years of age: adjuvanted TIV or cell-propagated QIV. 
In children less than 18 years of age, the $V E$ ranged from $39 \%$ ( $95 \% \mathrm{Cl}:-19$ to 69 ) in UK-PC (2-17-year-olds) to $95 \%$ (95\% Cl: 63 to 99 ) in DK-PC (0-17-year-olds) (Table 2).The VE in EU-PC and ES-PC target groups for influenza vaccination was $49 \%$ (95\% Cl: 16 to 69) and $62 \%$ ( $95 \% \mathrm{Cl}: 24$ to 82 ), respectively.

\section{Hospital settings}

For all ages, VE against laboratory-confirmed hospitalised influenza A was $41 \%(95 \% \mathrm{Cl}: 27$ to 52$)$ in $\mathrm{DK}-\mathrm{H}$. For older adults, VE was $37 \%(95 \% \mathrm{Cl}: 19$ to 50$)$ in DK-H and $62 \%(95 \% \mathrm{Cl}: 41$ to 76$)$ in $\mathrm{EU}-\mathrm{H}$.

\section{Influenza $\mathrm{A}(\mathrm{H} 1 \mathrm{N1})$ pdm09}

\section{Primary care settings}

For all ages, VE against laboratory-confirmed influenza $\mathrm{A}\left(\mathrm{H}_{1} \mathrm{~N}_{1}\right)$ pdmog ranged between $48 \%$ (95\% Cl: 18 to $68)$ in EU-PC and $75 \%$ (95\% Cl: 57 to 86) in DK-PC. The number of vaccinated cases in the UK-PC study was too small to provide a VE estimate.

The VE among children less than 18 years of age was $46 \%$ (95\% Cl: -51 to 80 ) in EU-PC (o-17 years) and $51 \%$ ( $95 \% \mathrm{Cl}-45$ to 83 ) in ES-PC (0-14 years). Among adults less than 65 years, VE was between $49 \%$ (95\% Cl: 1 to 74 ) in EU-PC (18-64 years) and 68\% (95\% Cl: 28 to 86 ) in ES-PC (15-64 years). VE for adults aged 65 years and older was $79 \%$ (95\% Cl: 37 to 93) in the DK-PC study. Target groups in the ES-PC had VE of $73 \%(95 \% \mathrm{Cl}: 40$ to 88$)$ against influenza $A\left(\mathrm{H}_{1} \mathrm{~N}_{1}\right)$ pdmog.

\section{Hospital settings}

For hospitalised patients aged 65 years and older, VE was $51 \%(95 \% \mathrm{Cl}: 4$ to 75$)$ in DK-H and $63 \%(95 \% \mathrm{Cl}$ : 40 to 77 ) in the EU-H study (Table 2). For hospitalised patients in DK-H aged 18 to 64 years, VE was 55\% (95\% $\mathrm{Cl}: 3$ to 79 ).

\section{Virological results}

Among the $212 \mathrm{~A}\left(\mathrm{H}_{1} \mathrm{~N}_{1}\right)$ pdmog viruses sequenced, 90\% $(n=190)$ belonged to genetic clade 6B.1A5A (Table 3) and none belonged to the same clade as the vaccine component (6B.1A1). Twenty viruses ( $9 \%$ ) belonged to the $6 \mathrm{~B} .1 \mathrm{~A}_{5} \mathrm{~B}$ clade and one virus (1\%) each to the 6B.1A6 and 6B.1A7 clades.

\section{Influenza $\mathrm{A}(\mathrm{H} 3 \mathrm{~N} 2)$}

\section{Primary care settings}

For patients of all ages, VE against influenza $A\left(\mathrm{H}_{3} \mathrm{~N}_{2}\right)$ ranged from $-58 \%(95 \% \mathrm{Cl}:-338$ to 43$)$ in ES-PC to $57 \%$ (95\% Cl: 27 to 75 ) in EU-PC. For children aged 2 to 17 years in the UK-PC, VE was 39\% (95\% Cl: -21 to 69). For those aged 18 to 64 years, VE was between $29 \%$ (95\% Cl: -19 to 57 ) in DK-PC and $71 \%(95 \% \mathrm{Cl}: 37$ to 87 ) in EU-PC. VE ranged from $12 \%$ ( $95 \% \mathrm{Cl}:-53$ to 49 ) in DK-PC to $21 \%$ ( $95 \% \mathrm{Cl}:-56$ to 60 ) in UK-PC in those aged 65 years and over. For target groups in the EU-PC, VE against influenza $\mathrm{A}\left(\mathrm{H}_{3} \mathrm{~N}_{2}\right)$ was $38 \%(95 \% \mathrm{Cl}:-21$ to 69) (Table 2).
Hospital settings

VE among hospitalised patients aged 65 years and older against influenza $\mathrm{A}\left(\mathrm{H}_{3} \mathrm{~N}_{2}\right)$ was between $-16 \%$ (95\% Cl: -80 to 25$)$ in DK-H and 60\% (95\% Cl: -69 to 90) in EU-H (Table 2).

Virological results

Of the 334 influenza $\mathrm{A}\left(\mathrm{H}_{3} \mathrm{~N}_{2}\right)$ viruses sequenced, $69 \%(n=231)$ belonged to the same genetic clade as the vaccine strain ( 3 C.3a), $20 \%(n=67)$ belonged to $3 C .2 a 1 b+T 131 K, 6 \%$ to $3 C .2 a 1 b+T 135 K-A(n=21)$ and $5 \%$ to $3 C \cdot 2 a 1 b+T 135 K-B(n=15)$. The distribution of (sub)clades varied by country, e.g. from $46 \%(n=31)$ in DK-H/DK-PC to $89 \%(n=150)$ in UK-PC for clade 3 C.3a, and with only 23 of $75 \mathrm{~A}\left(\mathrm{H}_{3} \mathrm{~N}_{2}\right)$ viruses sequenced overall in ES-PC.

\section{Influenza B}

\section{Primary care settings}

Sample sizes for influenza B were large enough to estimate VE in three studies in the primary care setting only (DK-PC, ES-PC and EU-PC). The VE against laboratoryconfirmed influenza $B$ for all age groups ranged from $62 \%(95 \% \mathrm{Cl}: 17$ to 83 ) in EU-PC to $83 \%$ (95\% Cl: 51 to 94 ) in DK-PC. For those aged $18-64$ years, VE was $12 \%$ in EU-PC (95\% Cl: -135 to 67 ) (Table 2). VE against B/ Victoria was $60 \%$ (95\% Cl: -12 to 86 ) (only estimated for EU-PC). The number of cases of B/Yamagata was too low for VE to be estimated.

\section{Virological results}

Of the 59 influenza B/Victoria viruses sequenced, 58 belonged to subgroup $1 \mathrm{~A}\left(\right.$ del $_{162-164)} \mathrm{B}$ and one belonged to the vaccine subclade $1 A($ del162-163).

\section{Sensitivity analyses}

Results with small sample sizes were subject to sensitivity analyses, all of which gave similar results (absolute difference range: $1-6 \%$ ).

\section{Discussion}

Our results for the $2019 / 20$ influenza season in six wellknown influenza studies across Europe indicate that interim VE against any laboratory-confirmed influenza among all ages in primary care and hospital settings ranged between $29 \%$ and $61 \%$, while VE was from $53 \%$ to $60 \%$ in vaccination target groups. The proportions of influenza (sub)types contributing to these overall results varied considerably by study.

Against influenza A (all subtypes) among all ages, point estimates for VE ranged between $30 \%$ and $60 \%$ in both types of settings, and they were slightly higher $(49-62 \%)$ in the target groups for vaccination. Against influenza $A\left(\mathrm{H}_{1} \mathrm{~N}_{1}\right)$ pdmog, VE point estimates among all ages ranged from $48 \%$ to $75 \%$, being slightly higher among older adults (aged 65 years and older) in DK-PC at $79 \%$ and slightly lower in children aged o to 17 years in EU-PC (46\%). There were varied results for VE against influenza $A\left(\mathrm{H}_{3} \mathrm{~N}_{2}\right)$. For patients of all ages 


\section{FIGURE 2}

Proportion of influenza virus (sub)types among cases, six European studies, interim influenza season 2019/20 (n=5,310)

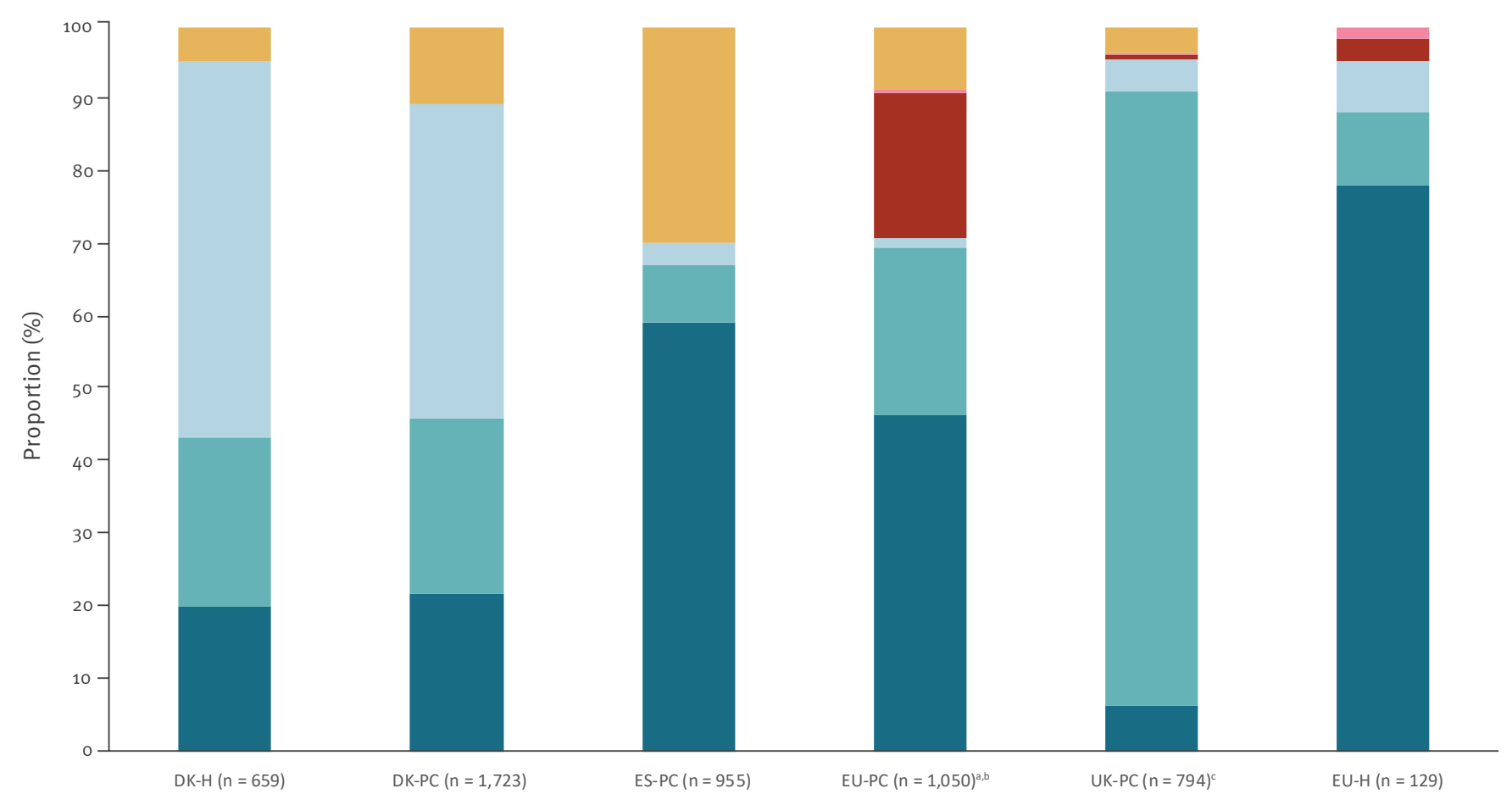

Study (n)

Influenza virus (sub)types and lineages:

A( $\left.\mathrm{H}_{1} \mathrm{~N}_{1}\right)$ pdmog $\quad \mathrm{A}\left(\mathrm{H}_{3} \mathrm{~N}_{2}\right) \quad$ A unsubtyped $\quad \mathrm{B} /$ Victoria $\quad \mathrm{B} /$ Yamagata $\quad$ B lineage unknown

DK-H: Denmark hospital study; DK-PC: Denmark primary care study; ES-PC: Spanish primary care study; UK-PC: United Kingdom primary care study; EU-H: European Union hospital multicentre I-MOVEstudy; EU-PC: European Union primary care multicentre I-MOVE study; I-MOVE: Influenza - Monitoring Vaccine Effectiveness in Europe.

246 of influenza $A\left(\mathrm{H}_{1} \mathrm{~N}_{1}\right)$ pdmo9, eight $A\left(\mathrm{H}_{3} \mathrm{~N}_{2}\right)$ and $79 \mathrm{~B}$ cases are also in ES-PC.

${ }^{b}$ Includes three co-infections. These, and two patients from one site, were not included in the $\mathrm{A}\left(\mathrm{H}_{3} \mathrm{~N} 2\right)$ analysis, but in the 'any influenza A' analysis.

c Includes 12 co-infections.

combined, two studies (one primary care, one hospital) had VE point estimates $<0 \%$, two (primary care) had $V E<30 \%$, and two (one primary care, one hospital) had $V E>50 \%$. The VE point estimate against $A\left(\mathrm{H}_{3} \mathrm{~N}_{2}\right)$ was highest among 18 to 64-year-olds in EU-PC (71\%). Against laboratory-confirmed influenza $B, V E$ among all ages ranged from $62 \%$ to $83 \%$ in primary care settings.

The VE point estimates against all influenza from three of four primary care studies (DK-PC, ES-PC and EU-PC) over all ages, at $53 \%$ to $61 \%$, are similar to VE point estimates from Canada (58\%) [15], and a little higher than those reported from the United States (US) (45\%) [16], noting that proportions of influenza (sub)types and proportions of study participants contributing to age groups may be slightly different across all studies. For older adults (aged 65 years and over), the six studies presented here had VE point estimates of $43 \%$ to $66 \%$ across all settings. This is similar to estimates from Finland, Sweden and Canada for this age group, at $41 \%$ [17], 44\% [18] and 60\% [15], respectively. It is also similar for those aged 50 years and over in the US, at $43 \%$ [16], noting that underlying proportions of influenza (sub)types are likely to be different across all studies.

The 2019/20 interim VE against influenza $A\left(\mathrm{H}_{1} \mathrm{~N}_{1}\right)$ pdmog was higher compared with the 2018/19 interim season estimates in most studies among all ages, except for the EU-PC study [19]. The VE against $A\left(\mathrm{H}_{1} \mathrm{~N}_{1}\right)$ pdmog was also higher among those aged 65 years and older in the hospital-based studies in the 2019/20 season compared with the previous season [19]. The main circulating genetic clade in the $2019 / 20$ studies is $6 \mathrm{~B}_{1} \mathrm{~A}_{5} \mathrm{~A}$ and to a lesser extent, $6 \mathrm{~B} .1 \mathrm{~A}_{5} \mathrm{~B}$, which although different from the vaccine strain, show good reactivity with ferret antiserum raised against the vaccine virus [20]. The $2019 / 20$ interim influenza $A\left(\mathrm{H}_{1} \mathrm{~N}_{1}\right)$ 


\section{TABLE 2A}

Interim vaccine effectiveness (VE) against all laboratory-confirmed influenza, influenza A, A(H1N1)pdm09, A(H3N2) and $\mathrm{B}$, by age group, target group for vaccination and by study, six European studies, influenza season 2019/20

\begin{tabular}{|c|c|c|c|c|c|c|c|c|c|c|}
\hline \multirow{2}{*}{ Influenza (sub)type and study } & \multirow{2}{*}{ Setting } & \multirow{2}{*}{ Study population ${ }^{\mathrm{a}}$} & \multicolumn{3}{|c|}{ Cases } & \multicolumn{3}{|c|}{ Controls } & \multirow{2}{*}{$\mathrm{VE}^{\mathrm{b}}$} & \multirow{2}{*}{$95 \% \mathrm{Cl}$} \\
\hline & & & All & Vacc & $\%$ & All & Vacc & $\%$ & & \\
\hline \multicolumn{11}{|l|}{ All influenza $(A$ and $B)$} \\
\hline \multirow{4}{*}{ DK-PCc } & \multirow{4}{*}{ PC } & All ages & 1,715 & 119 & 7 & 11,127 & 1,349 & 12 & 56 & 46 to 65 \\
\hline & & $0-17$ years & 669 & 1 & $\ll 1$ & 3,793 & 669 & 18 & 95 & 67 to 99 \\
\hline & & $18-64$ years & 862 & 48 & 6 & 5,436 & 480 & 9 & 58 & 43 to 69 \\
\hline & & $\geq 65$ years & 184 & 70 & 38 & 1,898 & 808 & 43 & 40 & 18 to 57 \\
\hline \multirow{4}{*}{ ES-PC } & \multirow{4}{*}{ PC } & All ages & 955 & 46 & 5 & 843 & 79 & 9 & 61 & 37 to 76 \\
\hline & & $0-14$ years & 416 & 14 & 3 & 298 & 15 & 5 & 67 & 18 to 87 \\
\hline & & $15-64$ years & 513 & 19 & 4 & 473 & 27 & 6 & 55 & 10 to 77 \\
\hline & & Target group ${ }^{d}$ & 105 & 27 & 26 & 181 & 57 & 31 & 60 & 22 to 79 \\
\hline \multirow{4}{*}{ EU-PC } & \multirow{4}{*}{$\mathrm{PC}$} & All ages & 1,052 & 76 & 7 & 1,935 & 211 & 11 & 53 & 34 to 67 \\
\hline & & $0-17$ years & 419 & 12 & 3 & 810 & 28 & 4 & 64 & 16 to 85 \\
\hline & & $18-64$ years & 566 & 33 & 6 & 920 & 81 & 9 & 51 & 21 to 70 \\
\hline & & Target group ${ }^{d}$ & 197 & 52 & 26 & 509 & 158 & 31 & 53 & 26 to 70 \\
\hline \multirow{4}{*}{ UK-PC } & \multirow{4}{*}{ PC } & All ages & 782 & 114 & 15 & 1,766 & 308 & 17 & 29 & 4 to 48 \\
\hline & & $2-17$ years & 303 & 24 & 8 & 358 & 28 & 8 & 37 & -21 to 67 \\
\hline & & $18-64$ years & 379 & 44 & 12 & 937 & 119 & 13 & 36 & 1 to 58 \\
\hline & & $\geq 65$ years & 72 & 46 & 64 & 281 & 161 & 57 & 26 & -44 to 62 \\
\hline \multirow{3}{*}{$\mathrm{DK}-\mathrm{H}^{\mathrm{c}}$} & \multirow{3}{*}{$\mathrm{H}$} & All ages & 658 & 168 & 26 & 10,103 & 2,745 & 27 & 40 & 27 to 51 \\
\hline & & $18-64$ years & 237 & 30 & 13 & 3,397 & 533 & 16 & 48 & 22 to 65 \\
\hline & & $\geq 65$ years & 315 & 134 & 43 & 5,008 & 2,166 & 43 & 35 & 17 to 49 \\
\hline $\mathrm{EU}-\mathrm{H}^{\mathrm{c}}$ & $\mathrm{H}$ & $\geq 65$ years & 128 & 54 & 42 & 473 & 312 & 66 & 60 & 39 to 74 \\
\hline \multicolumn{11}{|l|}{ Influenza A } \\
\hline \multirow{4}{*}{ DK-PC } & \multirow{4}{*}{$\mathrm{PC}$} & All ages & 1,540 & 115 & 8 & 11,127 & 1,349 & 12 & 54 & 43 to 63 \\
\hline & & $0-17$ years & 579 & 1 & $\ll 1$ & 3,793 & 61 & 2 & 95 & 63 to 99 \\
\hline & & $18-64$ years & 786 & 47 & 6 & 5,436 & 480 & 9 & 54 & 38 to 67 \\
\hline & & $\geq 65$ years & 175 & 67 & 38 & 1,898 & 808 & 43 & 41 & 18 to 57 \\
\hline \multirow{4}{*}{$E S-P C$} & & All ages & 670 & 40 & 6 & 843 & 79 & 9 & 60 & 34 to 76 \\
\hline & $P C$ & $0-14$ years & 244 & 12 & 5 & 298 & 15 & 5 & 48 & -39 to 81 \\
\hline & & $15-64$ years & 400 & 15 & 4 & 473 & 27 & 6 & 62 & 20 to 82 \\
\hline & & Target group ${ }^{d}$ & 90 & 23 & 26 & 181 & 57 & 31 & 62 & 24 to 82 \\
\hline & & All ages & 746 & 67 & 9 & 1,906 & 210 & 11 & 53 & 32 to 67 \\
\hline FU-PC & $P S$ & $0-17$ years & 261 & 10 & 4 & 800 & 28 & 4 & 53 & -19 to 81 \\
\hline & & $18-64$ years & 426 & 27 & 6 & 903 & 81 & 9 & 60 & 32 to 76 \\
\hline & & Target group ${ }^{d}$ & 161 & 46 & 29 & 503 & 157 & 31 & 49 & 16 to 69 \\
\hline & & All ages & 756 & 110 & 15 & 1,766 & 308 & 17 & 30 & 4 to 49 \\
\hline UK_PC & $P S$ & $2-17$ years & 294 & 23 & 8 & 358 & 28 & 8 & 39 & -19 to 69 \\
\hline & & $18-64$ years & 364 & 42 & 12 & 937 & 119 & 13 & 38 & 3 to 60 \\
\hline & & $\geq 65$ years & 70 & 45 & 64 & 281 & 161 & 57 & 24 & -49 to 61 \\
\hline & & All ages & 629 & 162 & 26 & 10,103 & 2,745 & 27 & 41 & 27 to 52 \\
\hline DK-H & Hospital & $18-64$ years & 226 & 29 & 13 & 3,397 & 533 & 16 & 47 & 21 to 65 \\
\hline & & $\geq 65$ years & 306 & 129 & 42 & 5,008 & 2,166 & 43 & 37 & 19 to 50 \\
\hline $\mathrm{EU}-\mathrm{H}^{\mathrm{c}}$ & Hospital & $\geq 65$ years & 122 & 50 & 41 & 473 & 312 & 66 & 62 & 41 to 76 \\
\hline
\end{tabular}

$\mathrm{Cl}$ : confidence interval; DK-PC: Denmark primary care study; DK-H: Denmark hospital study; ES-PC: Spain primary care study; EU-H: European Union hospital multicentre I-MOVE study; EU-PC: European Union primary care multicentre I-MOVE study; I-MOVE: Influenza - Monitoring Vaccine Effectiveness in Europe; LAIV4: quadrivalent live attenuated influenza vaccine; NC: not calculated (percentages not shown where denominators (60); PC: primary care; UK-PC: United Kingdom primary care study; Vacc: vaccinated; VE: vaccine effectiveness.

Countries included in EU-H analysis for any influenza, influenza A and influenza $\mathrm{A}\left(\mathrm{H}_{3} \mathrm{~N}_{2}\right)$ : Romania and Spain. For analysis against influenza $\mathrm{A}\left(\mathrm{H}_{1} \mathrm{~N}_{1}\right)$ pdmo9: Spain only.

Countries included in EU-PC analysis for all influenza, influenza A and $A\left(\mathrm{H}_{1} \mathrm{~N}_{1}\right)$ pdmog: France, Germany, Ireland, the Netherlands, Portugal, Romania, Spain and Sweden. For analysis against influenza $\mathrm{A}\left(\mathrm{H}_{3} \mathrm{~N}_{2}\right)$ : France, Germany, Ireland, the Netherlands, Romania, Spain and Sweden are included. For analysis against influenza B: France, Germany, Ireland, Portugal, Romania, Spain and Sweden. For analysis against influenza B/Victoria: France, Germany, Ireland, Portugal, Romania and Sweden.

${ }^{a}$ Age-specific or target group-specific VE was not included for overall or (sub)type-specific VE in some study sites, where sample size did not allow estimation of VE.

b For details of adjustment variables, see Table 1.

c Some records with missing values were dropped from this analysis.

${ }^{\mathrm{d}}$ Groups targeted by seasonal influenza vaccination as defined locally in the studies and study sites. 
Interim vaccine effectiveness (VE) against all laboratory-confirmed influenza, influenza A, A(H1N1)pdm09, A(H3N2) and $\mathrm{B}$, by age group, target group for vaccination and by study, six European studies, influenza season 2019/20

\begin{tabular}{|c|c|c|c|c|c|c|c|c|c|c|}
\hline \multirow{2}{*}{ Influenza (sub)type and study } & \multirow{2}{*}{ Setting } & \multirow{2}{*}{ Study population ${ }^{a}$} & \multicolumn{3}{|c|}{ Cases } & \multicolumn{3}{|c|}{ Controls } & \multirow{2}{*}{$\mathrm{VE}^{\mathrm{b}}$} & \multirow{2}{*}{$95 \% \mathrm{Cl}$} \\
\hline & & & All & Vacc & $\%$ & All & Vacc & $\%$ & & \\
\hline \multicolumn{11}{|l|}{ Influenza A(H1N1)pdmo9 } \\
\hline \multirow{3}{*}{ DK-PC } & \multirow{3}{*}{ PC } & All ages & 373 & 14 & 4 & 11,127 & 1,349 & 12 & 75 & 57 to 86 \\
\hline & & $18-64$ years & 229 & 10 & 4 & 5,436 & 480 & 9 & 67 & 38 to 83 \\
\hline & & $\geq 65$ years & 28 & 4 & NC & 1,898 & 808 & 43 & 79 & 37 to 93 \\
\hline \multirow{4}{*}{ ES-PC } & \multirow{4}{*}{ PC } & All ages & 566 & 30 & 5 & 843 & 79 & 9 & 69 & 46 to 82 \\
\hline & & $0-14$ years & 198 & 10 & 5 & 298 & 15 & 5 & 51 & -45 to 83 \\
\hline & & $15-64$ years & 349 & 12 & 3 & 473 & 27 & 6 & 68 & 28 to 86 \\
\hline & & Target group $^{\mathrm{d}}$ & 76 & 17 & 22 & 181 & 57 & 31 & 73 & 40 to 88 \\
\hline \multirow{3}{*}{ EU-PC } & \multirow{3}{*}{ PC } & All ages & 487 & 33 & 7 & 1,906 & 210 & 11 & 48 & 18 to 68 \\
\hline & & $0-17$ years & 172 & 9 & 5 & 786 & 27 & 3 & 46 & -51 to 80 \\
\hline & & $18-64$ years & 292 & 14 & 5 & 903 & 81 & 9 & 49 & 1 to 74 \\
\hline \multirow{3}{*}{ DK-H } & \multirow{3}{*}{ Hospital } & All ages & 132 & 22 & 17 & 10,103 & 2,745 & 27 & 54 & 24 to 72 \\
\hline & & $18-64$ years & 68 & 8 & 12 & 3,397 & 533 & 16 & 55 & 3 to 79 \\
\hline & & $\geq 65$ years & 44 & 12 & NC & 5,008 & 2,166 & 43 & 51 & 4 to 75 \\
\hline $\mathrm{EU}-\mathrm{H}^{\mathrm{c}}$ & Hospital & $\geq 65$ years & 98 & 42 & 43 & 445 & 303 & 68 & 63 & 40 to 77 \\
\hline \multicolumn{11}{|l|}{ Influenza $\mathrm{A}\left(\mathrm{H}_{3} \mathrm{~N}_{2}\right)$} \\
\hline \multirow{3}{*}{ DK-PC } & \multirow{3}{*}{ PC } & All ages & 418 & 45 & 11 & 11,127 & 1,349 & 12 & 27 & -4 to 49 \\
\hline & & $18-64$ years & 190 & 17 & 9 & 5,436 & 480 & 9 & 29 & -19 to 57 \\
\hline & & $\geq 65$ years & 55 & 27 & NC & 1,898 & 808 & 43 & 12 & -53 to 49 \\
\hline ES-PC & $\mathrm{PC}$ & All ages & 75 & 10 & 13 & 799 & 79 & 10 & -58 & -338 to 43 \\
\hline \multirow{3}{*}{ EU-PC } & \multirow{3}{*}{ PC } & All ages & 244 & 33 & 14 & 1,772 & 180 & 10 & 57 & 27 to 75 \\
\hline & & $18-64$ years & 125 & 12 & 10 & 834 & 75 & 9 & 71 & 37 to 87 \\
\hline & & Target group ${ }^{d}$ & 70 & 28 & 40 & 431 & 126 & 29 & 38 & -21 to 69 \\
\hline \multirow{4}{*}{ UK-PC } & \multirow{4}{*}{ PC } & All ages & 675 & 103 & 15 & 1,766 & 308 & 17 & 25 & -3 to 46 \\
\hline & & $2-17$ years & 273 & 22 & 8 & 358 & 28 & 8 & 39 & -21 to 69 \\
\hline & & $18-64$ years & 308 & 38 & 12 & 937 & 119 & 13 & 31 & -8 to 56 \\
\hline & & $\geq 65$ years & 66 & 43 & 65 & 281 & 161 & 57 & 21 & -56 to 60 \\
\hline \multirow{2}{*}{ DK-H } & Hosnital & All ages & 154 & 59 & 38 & 10,103 & 2,745 & 27 & -13 & -58 to 19 \\
\hline & & $\geq 65$ years & 89 & 53 & 60 & 5,008 & 2,166 & 43 & -16 & -80 to 25 \\
\hline $\mathrm{EU}-\mathrm{H}^{\mathrm{c}}$ & Hospital & $\geq 65$ years & 12 & 4 & NC & 313 & 199 & 64 & 60 & -69 to 90 \\
\hline Influenza B & & & & & & & & & & \\
\hline DK-PC & $P C$ & All ages & 183 & 4 & 2 & 11,127 & 1,349 & 12 & 83 & 51 to 94 \\
\hline ES-PC & $\mathrm{PC}$ & All ages & 285 & 6 & 2 & 843 & 79 & 9 & 66 & 7 to 87 \\
\hline EULPC & PC & All ages & 305 & 9 & 3 & 1,373 & 169 & 12 & 62 & 17 to 83 \\
\hline EU-PC & $P C$ & $18-64$ years & 138 & 6 & 4 & 658 & 64 & 10 & 12 & -135 to 67 \\
\hline Influenza B Victoria & & & & & & & & & & \\
\hline EU-PCc & $P C$ & All ages & 209 & 5 & 2 & 1,190 & 141 & 12 & 60 & -12 to 86 \\
\hline
\end{tabular}

$\mathrm{Cl}$ : confidence interval; DK-PC: Denmark primary care study; DK-H: Denmark hospital study; ES-PC: Spain primary care study; EU-H: European Union hospital multicentre I-MOVE study; EU-PC: European Union primary care multicentre I-MOVE study; I-MOVE: Influenza - Monitoring Vaccine Effectiveness in Europe; LAIV4: quadrivalent live attenuated influenza vaccine; NC: not calculated (percentages not shown where denominators (60); PC: primary care; UK-PC: United Kingdom primary care study; Vacc: vaccinated; VE: vaccine effectiveness.

Countries included in EU-H analysis for any influenza, influenza $A$ and influenza $A\left(\mathrm{H}_{3} \mathrm{~N}_{2}\right)$ : Romania and Spain. For analysis against influenza $\mathrm{A}\left(\mathrm{H}_{1} \mathrm{~N} 1\right)$ pdmo9: Spain only.

Countries included in EU-PC analysis for all influenza, influenza A and A(H1N1)pdmog: France, Germany, Ireland, the Netherlands, Portugal, Romania, Spain and Sweden. For analysis against influenza $\mathrm{A}\left(\mathrm{H}_{3} \mathrm{~N}_{2}\right)$ : France, Germany, Ireland, the Netherlands, Romania, Spain and Sweden are included. For analysis against influenza B: France, Germany, Ireland, Portugal, Romania, Spain and Sweden. For analysis against influenza B/Victoria: France, Germany, Ireland, Portugal, Romania and Sweden.

a Age-specific or target group-specific VE was not included for overall or (sub)type-specific VE in some study sites, where sample size did not allow estimation of VE.

${ }^{\mathrm{b}}$ For details of adjustment variables, see Table 1.

c Some records with missing values were dropped from this analysis.

${ }^{\mathrm{d}}$ Groups targeted by seasonal influenza vaccination as defined locally in the studies and study sites. 
pdmog VE in Canada [15] and the US [16] was $44 \%$ and $37 \%$, respectively. These overall results are lower than the DK-PC and ES-PC results, but are more comparable with the EU-PC results (48\%). In the US, there was some indication of lower VE among younger adults (1849 years) with VE being 5\% [16]. None of the studies reported in this article indicate a much lower $A\left(\mathrm{H}_{1} \mathrm{~N}_{1}\right)$ pdmog VE among younger adults. End-of-season overall results as well as clade/genetic variant-specific results and birth cohort-specific VE will help understand differences between studies at international level.

Unlike observed estimates in the 2018/19 season, in which three of five studies reporting $\mathrm{A}\left(\mathrm{H}_{3} \mathrm{~N}_{2}\right)$ cases had VE below zero and all were below 50\% [19], two of six 2019/20 interim study results were below zero, two were between $25 \%$ and $50 \%$, and two were between $50 \%$ and $60 \%$. The EU-PC and the ES-PC studies showed very different point estimates of $A\left(\mathrm{H}_{3} \mathrm{~N}_{2}\right)$ VE among all ages; however, there were only eight cases in common across these studies. There is considerable variation in the VE estimates against $A\left(\mathrm{H}_{3} \mathrm{~N}_{2}\right)$ presented here, which may go hand-in-hand with the considerable genetic diversity observed. While $A\left(\mathrm{H}_{3} \mathrm{~N}_{2}\right)$ viruses remain difficult to characterise antigenically [20], reports suggest that the 3 C.3a circulating viruses were antigenically similar to the vaccine virus. While a higher VE against $\mathrm{A}\left(\mathrm{H}_{3} \mathrm{~N}_{2}\right)$ among studies with high proportions of $3 \mathrm{C} .3 \mathrm{a}$ characterised viruses might be anticipated, this was not observed everywhere. The other viruses circulating belonged to the $3 \mathrm{C} .2 \mathrm{a} 1 \mathrm{~b}$ clade, most with additional substitutions. These viruses are more genetically distinct from the vaccine virus and therefore antigenically less similar. However, $2019 / 20$ interim VE from Canada against $\mathrm{A}\left(\mathrm{H}_{3} \mathrm{~N}_{2}\right)$ was $62 \%$, and $94 \%$ of the 80 viruses sequenced in Canada belonged to the 3 C.2a1b clade. While clade-specific VE estimates at the end of the $2019 / 20$ season could elucidate whether different circulating clades of $A\left(\mathrm{H}_{3} \mathrm{~N}_{2}\right)$ viruses across the region explain the differences in $V E$ against $A\left(\mathrm{H}_{3} \mathrm{~N}_{2}\right)$ observed here in these studies, some of the observed differences in interim VE may indicate that further explanations, such as immunological cohort effects [21], need to be investigated.

Recent vaccine seed $\mathrm{A}\left(\mathrm{H}_{3} \mathrm{~N}_{2}\right)$ viruses have developed adaptions during propagation in eggs, potentially negatively affecting VE [22]. Cell-propagated vaccines were used in some studies, but there was insufficient data to estimate vaccine type-specific VE.

VE against influenza B was $>60 \%$ among all ages in primary care, with a lower VE among those aged 18 to 64 years in EU-PC. However, sample size was lower in this age group and the low VE may possibly be a result of random variation. The high overall VE was comparable with 2019/20 interim VE against influenza B in Canada (69\%) [15]. In the US, overall VE against B/Victoria was lower, at 50\% [16].
In studies where lineage was available, the vast majority of circulating influenza B belonged to the B/Victoria lineage, which was the lineage included in the trivalent vaccine but of another subgroup. The quadrivalent vaccine was used widely in Europe, however because of low circulation of B/Yamagata viruses, the VE of quadrivalent and trivalent vaccines could not be compared in the context of VE against trivalent lineage-mismatched influenza B. Among the sequenced B/Victoria viruses,

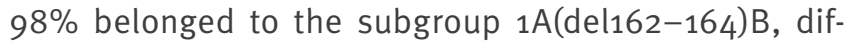
fering from the vaccine virus by a further amino acid deletion, and being antigenically different [3,23,24]. Nevertheless, human serology studies show some evidence of cross-reactivity between the vaccine and the circulating B/Victoria viruses $[20,23,24]$.

The early start of the season in most European countries included in these six studies [5] resulted in higher incidence and greater precision for interim VE estimates than in 2018/19, although some studies did have lower sample size for some subgroups in this interim analysis. Each study used study-specific criteria to define if a sample size was too small to attempt to estimate VE. Where VE results were presented, and sample size was small, sensitivity analyses were used to address potential small sample bias where appropriate. Endof-season estimates will have higher sample size and provide more robust estimates. Residual confounding and bias are known limitations potentially present in all observational studies.

Vaccination remains the key successful method of influenza prevention, with one to two-thirds of all vaccinated individuals receiving protection during the 2019/20 influenza season. Promotion of influenza vaccination should be maintainted in line with national guidelines and recommendations in all European countries with ongoing influenza virus circulation. Given the variation in VE estimates against $A\left(\mathrm{H}_{3} \mathrm{~N}_{2}\right)$, it remains important that when national guidelines indicate neuraminidase inhibitors to be used, they are used regardless of vaccination status as prophylaxis and therapy where there is influenza $\mathrm{A}\left(\mathrm{H}_{3} \mathrm{~N}_{2}\right)$ virus circulation to help prevent severe outcomes [1].

Bi-annual reports on influenza VE in prior and existing seasons are provided by the Global Influenza VE (GIVE) Collaboration. The February 2020 GIVE report included interim VE results presented here to help inform the WHO Vaccine Strain Selection Committee meeting of 24 to 27 February 2020 in Geneva. For the 2020/21 northern hemisphere season, WHO provided specific recommendations for egg-based, cell-based and recombinant-based vaccines [25]. Compared with the northern hemisphere 2019/20 trivalent vaccine recommendations, all components for the 2020/21 trivalent vaccine have been changed. For influenza $\mathrm{A}\left(\mathrm{H}_{1} \mathrm{~N}_{1}\right)$ pdmo9, WHO recommended A/GuangdongMaonan/SWL1536/2019(H1N1)pdmo9-like virus for egg-based vaccines and $\mathrm{A} / \mathrm{Hawaii} / 70 / 2019\left(\mathrm{H}_{1} \mathrm{~N}_{1}\right)$ pdmog-like virus for cell-based or recombinant-based 
vaccines, which are 6B.1A5A viruses, harbouring additional D187A and Q189E substitutions. For influenza $\mathrm{A}\left(\mathrm{H}_{3} \mathrm{~N}_{2}\right)$, WHO recommended $\mathrm{A} /$ HongKong/2671/2019 $\left(\mathrm{H}_{3} \mathrm{~N}_{2}\right)$-like virus for egg-based vaccines and $\mathrm{A} /$

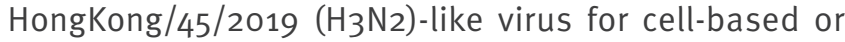
recombinant-based vaccines, both $3 \mathrm{C} .2 \mathrm{a} 1 \mathrm{~b}+\mathrm{T}_{135} \mathrm{~K}$-B viruses, harbouring S137F, A138S and F193SHA substitutions. For the 2020 southern hemisphere influenza vaccine, WHO recommended for both 2020/21 northern hemisphere trivalent and quadrivalent vaccines a $\mathrm{B} /$ Washington/02/2019-like (B/Victoria lineage) virus (a three amino acid deletion virus), and additionally, a B/ Phuket/3073/2013-like (B/Yamagata lineage) virus for the quadrivalent vaccine [25].

The VE and antigenic studies at the end of the 2019/20 season will help to explain the differences in age-, subtype- and study-specific VE estimates presented here. In order to be prepared for the next season in the northern hemisphere, we should continue to monitor the genetic diversity of the 2020 southern hemisphere influenza viruses and their influenza VE.

\section{European IVE group}

\section{Denmark}

DK-H and DK-PC studies:

Hanne-Dorthe Emborg, Department of Infectious Disease Epidemiology and Prevention, Statens Serum Institut, Copenhagen

Ramona Trebbien, Department of Virus and Microbiological Special diagnostics, National Influenza Center, Statens Serum Institut, Copenhagen

Daniel Thomas Lopez, Department of Virus and Microbiological Special diagnostics, National Influenza Center, Statens Serum Institut, Copenhagen; European Public Health Microbiology Training Programme (EUPHEM), European Centre for Disease Prevention and Control (ECDC), Stockholm, Sweden

Tyra Grove Krause, Department of Infectious Disease Epidemiology and Prevention, Statens Serum Institut, Copenhagen

France

\section{EU-PC study:}

Alessandra Falchi, EA 7310, Laboratoire de Virologie, Université de Corse-Inserm, Corte

Shirley Masse, EA 7310, Laboratoire de Virologie, Université de Corse-Inserm, Corte

Natacha Villechenaud, EA 7310, Laboratoire de Virologie, Université de Corse-Inserm, Corte

Ana-Maria Vilcu, INSERM, Sorbonne Université, Institut Pierre Louis d'Epidémiologie et de Santé Publique (IPLESP UMRS 1136), Paris

Cécile Souty, Sorbonne Université, INSERM, Institut Pierre Louis d'Epidémiologie et de Santé Publique (IPLESP UMRS 1136), Paris

Thierry Blanchon, Sorbonne Université, INSERM, Institut Pierre Louis d'Epidémiologie et de Santé Publique (IPLESP UMRS 1136), Paris

Titouan Launay, Sorbonne Université, INSERM, Institut Pierre Louis d'Epidémiologie et de Santé Publique (IPLESP UMRS 1136), Paris

Sylvie van der Werf, Unité de Génétique Moléculaire des Virus à ARN, UMR 3569 CNRS, Université de Paris, Institut
Pasteur, Paris; CNR des virus des infections respiratoires, Institut Pasteur, Paris

Vincent Enouf, Unité de Génétique Moléculaire des Virus à ARN, UMR 3569 CNRS, Université de Paris, Institut Pasteur, Paris; CNR des virus des infections respiratoires, Institut Pasteur, Paris

Sylvie Behillil, Unité de Génétique Moléculaire des Virus à ARN, UMR 3569 CNRS, Université de Paris, Institut Pasteur, Paris; CNR des virus des infections respiratoires, Institut Pasteur, Paris.

Bruno Lina, Laboratoire de Virologie, CNR des virus des infections respiratoires, Institut des Agents Infectieux, Groupement Hospitalier Nord des HCL, Lyon, France; Laboratoire Virpath, CIRI Inserm U1111, CNRS 5308, ENS, UCBL, Faculté de Médecine Lyon Est, Université de Lyon, Lyon

Martine Valette, Laboratoire de Virologie, CNR des virus des infections respiratoires, Institut des Agents Infectieux, Groupement Hospitalier Nord des HCL, Lyon

Epiconcept

EU-PC and EU-H studies:

Marta Valenciano, Alain Moren, Epiconcept, Paris, France

EU-PC study:

Esther Kissling, Epiconcept, Paris, France

EU-H study:

Angela Rose, Epiconcept, Paris, France

European Centre for Disease Prevention and Control

EU-PC study:

Pasi Penttinen, ECDC, Stockholm, Sweden

Germany

EU-PC study:

Silke Buda, Department for Infectious Disease Epidemiology, Respiratory Infections Unit, Robert Koch Institute, Berlin

Ute Preuss, Department for Infectious Disease Epidemiology, Respiratory Infections Unit, Robert Koch Institute, Berlin

Kristin Tolksdorf, Department for Infectious Disease Epidemiology, Respiratory Infections Unit, Robert Koch Institute, Berlin

Barbara Biere, National Reference Center for Influenza, Robert Koch Institute, Berlin

Ralf Duerrwald, National Reference Center for Influenza, Robert Koch Institute, Berlin

Maria Smallfield, National Reference Center for Influenza, Robert Koch Institute, Berlin

Marianne Wedde, National Reference Center for Influenza, Robert Koch Institute, Berlin

Ireland

EU-PC study:

Lisa Domegan, HSE-Health Protection Surveillance Centre, Dublin; European Programme for Intervention Epidemiology Training (EPIET), European Centre for Disease Prevention and Control(ECDC), Stockholm, Sweden

Rachel Fiegenbaum, HSE-Health Protection Surveillance Centre, Dublin

Joan O’Donnell, HSE-Health Protection Surveillance Centre, Dublin

Michael Joyce, Irish College of General Practitioners, Dublin Olga Levis, Irish College of General Practitioners, Dublin

Claire Collins, Irish College of General Practitioners, Dublin

Charlene Bennett, National Virus Reference Laboratory, University College Dublin, Dublin 
Joanne Moran, National Virus Reference Laboratory, University College Dublin, Dublin

Grainne Tuite, National Virus Reference Laboratory, University College Dublin, Dublin

Jeff Connell, National Virus Reference Laboratory, University College Dublin, Dublin

Cillian de Gascun, National Virus Reference Laboratory, University College Dublin, Dublin

The Netherlands

EU-PC study:

Adam Meijer, National Institute for Public Health and the Environment (RIVM), Bilthoven

Marit de Lange, National Institute for Public Health and the Environment (RIVM), Bilthoven

Sharon van den Brink, National Institute for Public Health and the Environment (RIVM), Bilthoven

Frederika Dijkstra, National Institute for Public Health and the Environment (RIVM), Bilthoven

Mariette Hooiveld, Nivel (the Netherlands Institute for Health Services Research), Utrecht

Portugal

EU-PC study:

Ana Paula Rodrigues, Departamento de Epidemiologia, Instituto Nacional de Saúde Dr Ricardo Jorge, Lisbon

Ausenda Machado, Departamento de Epidemiologia, Instituto Nacional de Saúde Dr Ricardo Jorge, Lisbon

Baltazar Nunes, Departamento de Epidemiologia, Instituto Nacional de Saúde Dr Ricardo Jorge, Lisbon

Irina Kislaya, Departamento de Epidemiologia, Instituto Nacional de Saúde Dr Ricardo Jorge, Lisbon

Verónica Gomez, Departamento de Epidemiologia, Instituto Nacional de Saúde Dr Ricardo Jorge, Lisbon

Inês Costa, Departamento de Doenças Infeciosas, Instituto Nacional de Saúde Dr Ricardo Jorge, Lisbon

Patrícia Conde, Departamento de Doenças Infeciosas, Instituto Nacional de Saúde Dr Ricardo Jorge, Lisbon

Paula Cristóvão, Departamento de Doenças Infeciosas, Instituto Nacional de Saúde Dr Ricardo Jorge, Lisbon

Pedro Pechirra, Departamento de Doenças Infeciosas, Instituto Nacional de Saúde Dr Ricardo Jorge, Lisbon

Raquel Guiomar, Departamento de Doenças Infeciosas, Instituto Nacional de Saúde Dr Ricardo Jorge, Lisbon

Romania

EU-PC and EU-H studies:

Mihaela Lazar, “Cantacuzino" National Medico-Military Institute for Research and Development, Bucharest

Carmen Maria Cherciu, "Cantacuzino" National MedicoMilitary Institute for Research and Development, Bucharest

Maria Elena Mihai, “Cantacuzino" National Medico-Military Institute for Research and Development, Bucharest

EU-H study:

Elena Duca, Clinical Hospital of Infectious Diseases "Sf Parascheva", Iasi

Mihaela Catalina Luca, Clinical Hospital of Infectious Diseases “Sf Parascheva”, Iasi

Maria Gradinaru, Clinical Hospital of Infectious Diseases "Sf Parascheva", lasi

Izabela Loghin, Clinical Hospital of Infectious Diseases "Sf Parascheva", Iasi
Carmen Manciuc, Clinical Hospital of Infectious Diseases "Sf Parascheva", lasi

Gratiela Tardei, Clinical Hospital of Infectious Diseases “Dr Victor Babes", Bucharest

Maria Nica, Clinical Hospital of Infectious Diseases "Dr Victor Babes", Bucharest

Simin-Aysel Florescu, Clinical Hospital of Infectious Diseases "Dr Victor Babes", Bucharest

Emanoil Ceausu, Clinical Hospital of Infectious Diseases " $\mathrm{Dr}$ Victor Babes", Bucharest

Spain

EU-PC (the cycEVA work group), ES-PC (the Spanish Influenza Sentinel Surveillance System) and EU-H studies:

Amparo Larrauri, National Centre of Epidemiology, Institute of Health Carlos III, CIBERESP, Madrid

Clara Mazagatos, National Centre of Epidemiology, Institute of Health Carlos III, CIBERESP, Madrid

Francisco Pozo, National Centre for Microbiology, National Influenza Reference Laboratory, WHO-National Influenza Centre, Institute of Health Carlos III, CIBERESP, Madrid

Inmaculada Casas, National Centre for Microbiology, National Influenza Reference Laboratory, WHO-National Influenza Centre, Institute of Health Carlos III, Madrid

EU-PC study (the cycEVA work group):

Luis García Comas, Dirección General de Salud Pública, Madrid

María Esther Insua Marisquerena, Dirección General de Salud Pública, Madrid

Juan Carlos Galán, Laboratorio Hospital Ramón y Cajal, CIBERESP, Madrid

Ma Dolores Folgueira, Laboratorio Hospital Doce de Octubre, Madrid

Carmen Quiñones Rubio, Dirección General de Salud Pública, Consumo y Cuidados de La Rioja, Logroño

Eva Martinez Ochoa, Dirección General de Salud Pública, Consumo y Cuidados de La Rioja, Logroño

Miriam Blasco, Laboratorio Hospital San Pedro de Logroño, Logroño

Jaume Gimenez Duran, Servicio de Epidemiología, Dirección General de Salud Pública, Mallorca

Juana Maria Vanrell, Servicio de Epidemiología, Dirección General de Salud Pública, Mallorca

Jordi Reina, Laboratorio del Hospital Son Espases, Mallorca

Daniel Castrillejo, Servicio de Epidemiología. DGSC, Consejería de Bienestar Social y Sanidad, Ciudad Autónoma de Melilla, Melilla

ES-PC study (the Spanish Influenza Sentinel Surveillance System):

Concha Delgado, National Centre of Epidemiology, Institute of Health Carlos III, CIBERESP

Jesus Oliva, National Centre of Epidemiology, Institute of Health Carlos III, CIBERESP

EU-H study:

Miriam Latorre-Millán, Instituto de Investigación Sanitaria (IIS) Aragón, Hospital Ủniversitario Miguel Servet, Zaragoza

Ana María Milagro, IIS Aragón, Hospital Universitario Miguel Servet, Zaragoza

Antonio Rezusta, IIS Aragón, Hospital Universitario Miguel Servet, Zaragoza

M. Amelia Fernández Sierra, Medecina Preventiva, Hospital Universitario Virgen de las Nieves, Granada 
Mercedes Pérez Ruiz, Hospital Universitario Virgen de las Nieves, Granada

María del Mar Rodríguez, Hospital Universitario Virgen de las Nieves, Granada

Spain - Navarra

EU-PC and EU-H studies:

Jesús Castilla, Instituto de Salud Pública de Navarra IdiSNA, CIBERESP, Pamplona

Manuel García Cenoz, Navarra Instituto de Salud Pública de Navarra - IdiSNA, CIBERESP, Pamplona

Itziar Casado, Instituto de Salud Pública de Navarra - IdiSNA, CIBERESP, Pamplona

Iván Martínez-Baz, Instituto de Salud Pública de Navarra IdiSNA, CIBERESP, Pamplona

Carlos Gómez Ibañez, Instituto de Salud Pública de Navarra, Pamplona

Nerea Iriarte, Instituto de Salud Pública de Navarra, Pamplona

Ana Navascués, Complejo Hospitalario de Navarra - IdiSNA, Pamplona

M Eugenia Portillo, Complejo Hospitalario de Navarra IdiSNA, Pamplona

Carmen Ezpeleta, Complejo Hospitalario de Navarra IdiSNA, Pamplona

Sweden

EU-PC study:

Mia Brytting, The Public Health Agency of Sweden, Stockholm

Åsa Wiman, The Public Health Agency of Sweden, Stockholm

Theresa Enkirch, The Public Health Agency of Sweden, Stockholm

United Kingdom

UK-PC study:

Jim McMenamin, Health Protection Scotland, Glasgow

Diogo F.P. Marques, Health Protection Scotland, Glasgow

Rory Gunson, West of Scotland Specialist Virology Centre, Glasgow

Chris Robertson, University of Strathclyde, Glasgow

Simon Cottrell, Public Health Wales, Cardiff

Catherine Moore, Public Health Wales, Cardiff

Mark O’Doherty, Public Health Agency Northern Ireland, Belfast

Jillian Johnston, Public Health Agency Northern Ireland, Belfast

Conall McCaughey, Regional Virology Laboratory, Belfast

Simon de Lusignan, University of Oxford, Oxford, Royal College of General Practitioners, London

Ivelina Yonova, University of Oxford, Oxford, Royal College of General Practitioners, London

Manasa Tripathy, University of Oxford, Oxford, Royal College of General Practitioners, London

Rachel Byford, University of Oxford, Oxford

Filipa Ferreria, University of Oxford, Oxford

Jamie LopezBernal, Public Health England, London

Richard Pebody, Public Health England, London

Mary Sinnathamby, Public Health England, London
Heather Whitaker, Public Health England, London

Nick Andrews, Public Health England, London

Joanna Ellis, Public Health England, London

Praveen SebastianPillai, Public Health England, London

Maria Zambon, Public Health England, London

\section{Acknowledgements}

All study teams are very grateful to all patients, general practitioners, paediatricians, hospital teams, laboratory teams, and regional epidemiologists who have contributed to the studies.

Special thanks from study teams to each of the following for their substantial contributions to the studies. In DK-PC and DK-H: Lasse Skafte Vestergaard. In ES-PC: all of the participants in the Spanish Influenza Sentinel Surveillance System. In EU-H, for Romania: Violeta Melinte, Elena Nedu, Cojanu Filofteia, Corneliu Popescu, Bianca Voinescu, Cristiana Cristea, Olivia Burcos, Delia Stanciu, Adelina Dogaru, Anca Hotescu, Nicoleta Mirea, Claudia Leulescu, Amalia Dascalu, Corina Oprisa, and Andreea Toderan. In EUPC, for the Netherlands: Wim van der Hoek, Daphne Reukers, Anne Carola Teirlinck, Janneke Hendriksen, Mariam Bagheri, Gabriel Goderski, Pieter Overduin, John Sluimer, Lisa Wijsman, and all other technicians performing specimen processing, molecular diagnostics and sequencing; for Romania: Elena Stoian, Catalina Pascu, Iulia Bistriceanu, Sorin Dinu, Mihaela Oprea, Luiza Ustea, Mirela Ene, Emilia Dobre, Oana Vitencu, Nicoleta Paraschiv, Viorel Alexandrescu; for Sweden: AnnaSara Carnahan, Elin Arvesen, and Tove Samuelsson Hagey. In UK-PC: Arlene Reynolds, Karen Voy, Louise Shaw-Primrose, Joseph Jasperse, Catherine Frew, and Samantha Shepherd.

Participating laboratories submitted their sequences to GISAID (www.gisaid.org) for easy sharing with the central laboratory in Madrid.

Test results for influenza virus were obtained from the Danish Microbiology Database (MiBa, http://miba.ssi.dk), which contains all electronic reports from departments of clinical microbiology in Denmark since 2010, and we acknowledge the collaboration with the MiBa Board of Representatives.

Special thanks also to Pernille Jorgensen and Sonja Olsen (WHO/Europe) for their support to the I-MOVE network.

Funding statement: ECDC contributed to funding some of the study sites and the coordination of the EU-PC study. WHO/ Europe contributed to funding the EU-H study. Epiconcept contributed to funding the EU-H study.

\section{Conflict of interest}

None declared.

\section{Authors' contributions}

Angela Rose: coordination of I-MOVE hospital network, study design, analysis of hospital data, interpretation of results, manuscript writing.

Esther Kissling: coordination of I-MOVE network, study design, analysis of primary care data, interpretation of results, manuscript writing. Both authors contributed equally to the study and manuscript. 
Hanne-Dorthe Emborg, Amparo Larrauri, Jim McMenamin, Ramona Trebbien, Clara Mazagatos and Heather Whitaker: coordination of their respective studies, data analysis and interpretation of results, read, contributed to and approved the final version of the manuscript.

Francisco Pozo: coordinated the I-MOVE virological analysis of the primary care study, read, contributed to and approved the final version of the manuscript.

European IVE group: (i) Primary care and hospital sites at national/regional level: data collection, data validation, results interpretation, review of manuscript. (ii) Laboratories: virological data collection, validation and analysis, genetic characterisation, interpretation of results, review of manuscript.

Marta Valenciano, Alain Moren: study design, coordination of I-MOVE network, interpretation of results, contribution to manuscript writing.

Pasi Penttinen: study design, interpretation of results, review of manuscript.

\section{References}

1. European Centre for Disease Prevention and Control (ECDC) Seasonal influenza vaccination and antiviral use in EU/EEA Member States: Overview of vaccine recommendations for 2017-2018 and vaccination coverage rates for 2015-2016 and 2016-2017 influenza seasons. Stockholm: ECDC; Nov 2018 Available from: https://ecdc.europa.eu/sites/portal/files/ documents/seasonal-influenza-antiviral-use-2018.pdf

2. Department of Health/National Health Service (DoH/NHS). The flu immunisation programme 2013/14 - extension to children. London: DoH/NHS; 26 Jul 2013. Available from: https://www. gov.uk/government/uploads/system/uploads/attachment data/file/225360/Children_s flu letter_2013.pdf

3. World Health Organization (WHO). Recommended composition of influenza virus vaccines for use in the 2019-2020 northern hemisphere influenza season. Geneva: WHO; Feb 2019. Available from: https://www.who.int/influenza/vaccines/virus/ recommendations/201902_recommendation.pdf?ua=1

4. World Health Organization (WHO). Addendum to the recommended composition of influenza virus vaccines for use in the 2019-2020 northern hemisphere influenza season. Geneva: WHO; 21 Mar 2019. Available from: https://www. who.int/influenza/vaccines/virus/recommendations/201902 recommendation_addendum.pdf?ua $=1$

5. European Centre for Disease Prevention and Control (ECDC) World Health Organization Regional Office for Europe (WHO/ Europe). Flu News Europe. Summary Week 04/2020 (20-26 January 2020). Stockholm/Geneva: ECDC/WHO/Europe; Jan 2020. Available from: https://flunewseurope.org/Archives

6. European Union (EU). Epiconcept. I-MOVE + Protocol for hospital-based test negative case control studies to measure seasonal influenza vaccine effectiveness against influenza laboratory confirmed SARI hospitalisation among the elderly across the European Union and European Economic Area Member States. Brussels: EU; Jun 2016. Available from: https://docs.google.com/viewer?a=v\&pid=sites\& srcid=ZXBp Y29uY2VwdC5mcnxpbW92ZXBsdXN8Z3g6NjgoNjQwM2QxZDRI $\mathrm{M} 2 \mathrm{JmMw}$

7. European Union (EU). Generic protocol for the test negative design case control studies to measure pandemic and seasonal influenza vaccine effectiveness in the European Union and European Economic Area Member States. Brussels: EU; 2015. Available from: https://drive.google.com/ file/d/oByv9pYYPpY4PM25qSXczQ394ToE/view

8. Jiménez-Jorge S, de Mateo S, Delgado-Sanz C, Pozo F, Casas I, Garcia-Cenoz M, et al. Estimating influenza vaccine effectiveness in Spain using sentinel surveillance data. Euro Surveill. 2015;20(28):21187. https://doi.org/10.2807/1560-7917. ES2015.20.28.21187 PMID: 26212144

9. Pebody R, Warburton F, Ellis J, Andrews N, Potts A, Cottrell S, et al. Effectiveness of seasonal influenza vaccine for adults and children in preventing laboratory-confirmed influenza in primary care in the United Kingdom: $2015 / 16$ end-of-season results. Euro Surveill. 2016;21(38):30348. https://doi. org/10.2807/1560-7917.ES.2016.21.38.30348 PMID: 27684603

10. Emborg HD, Krause TG, Nielsen L, Thomsen MK, Christiansen CB, Skov MN, et al. Influenza vaccine effectiveness in adults 65 years and older, Denmark, 2015/16 - a rapid epidemiological and virological assessment. Euro Surveill. 2016;21(14):30189. https://doi.org/10.2807/1560-7917.ES.2016.21.14.30189 PMID: 27101732

11. Fukushima W, Hirota Y. Basic principles of test-negative design in evaluating influenza vaccine effectiveness. Vaccine. 2017;35(36):4796-80o. https://doi.org/10.1016/j.vaccine.2017.07.003 PMID: 28818471

12. World Medical Association. World Medical Association Declaration of Helsinki: ethical principles for medical research involving human subjects. JAMA. 2013;310(20):2191-4. https:// doi.org/10.1001/jama.2013.281053 PMID: 24141714

13. Peduzzi P, Concato J, Feinstein AR, Holford TR. Importance of events per independent variable in proportional hazards regression analysis. II. Accuracy and precision of regression estimates. J Clin Epidemiol. 1995;48(12):1503-10. https://doi. org/10.1016/0895-4356(95)00048-8 PMID: 8543964

14. Covenay J. FIRTHLOGIT: Stata module to calculate bias reduction in logistic regression. Boston: Boston College Department of Economics; 2015.

15. Skowronski DM, Zou M, Sabaiduc S, Murti M, Olsha R Dickinson JA, et al. Interim estimates of 2019/20 vaccine effectiveness during early-season co-circulation of influenza $A$ and $B$ viruses, Canada, February 2020. Euro Surveill. 2020;25(7):2000103. https://doi.org/10.2807/1560-7917. ES.2020.25.7.2000103 PMID: 32098644

16. Dawood FS, Chung JR, Kim SS, Zimmerman RK, Nowalk MP, Jackson ML, et al. Interim Estimates of 2019-20 Seasonal Influenza Vaccine Effectiveness - United States, February 2020. MMWR Morb Mortal Wkly Rep. 2020;69(7):177-82. https://doi. org/10.15585/mmwr.mm6907a1 PMID: 32078591

17. Finnish Institute for Health \& Welfare (THL). Terveyden ja hyvinvoinnin laitos. [Up-to-date influenza review, updated 11 February 2020]. Helsinki: THL; Feb 2020. Finnish. Available from: https://thl.fi/fi/web/infektiotaudit-ja-rokotukset/ taudit-ja-torjunta/taudit-ja-taudinaiheuttajat-a-o/influenssa/ ajantasainen-influenssakatsaus

18. Smittskydd Stockholm. Säsongstatistik för influensa 2019/2020. [Seasonal statistics for influenza 2019/2020; week 6 2020. Stockholm: Smittskydd Stockholm; Feb 2020. Swedish. Available from: https://vardgivarguiden.se/globalassets/kunskapsstod/smittskydd/statistik/influensa/influensasasongen-2019-2020.pdf

19. Kissling E, Rose A, Emborg H-D, Gherasim A, Pebody R, Pozo $F$, et al. Interim 2018/19 influenza vaccine effectiveness: six European studies, October 2018 to January 2019. Euro Surveill. 2019;24(8):1900121. https://doi.org/10.2807/1560-7917. ES.2019.24.1900121 PMID: 30808440

20. European Centre for Disease Prevention and Control (ECDC). Surveillance report: Influenza virus characterisation. Stockholm: ECDC; Dec 2019. Available from: https://www. ecdc.europa.eu/sites/default/files/documents/influenza-viruscharacterisation-december-2019.pdf

21. Skowronski DM, Sabaiduc S, Leir S, Rose C, Zou M, Murti M, et al. Paradoxical clade- and age-specific vaccine effectiveness during the 2018/19 influenza $\mathrm{A}\left(\mathrm{H}_{3} \mathrm{~N}_{2}\right)$ epidemic in Canada: potential imprint-regulated effect of vaccine (I-REV). Euro Surveill. 2019;24(46):1900585. https://doi.org/10.2807/15607917.ES.2019.24.46.1900585 PMID: 31771709

22. Chen $Z$, Zhou H, Jin $\mathrm{H}$. The impact of key amino acid substitutions in the hemagglutinin of influenza $A\left(\mathrm{H}_{3} \mathrm{~N}_{2}\right)$ viruses on vaccine production and antibody response. Vaccine. 2010;28(24):4079-85. https://doi.org/10.1016/j.vac cine.2010.03.078 PMID: 20399830

23. Worldwide Influenza Centre. Report prepared for the WHO annual consultation on the composition of influenza vaccine for the northern hemisphere 2019-2020 [Internet]. London: The Francis Crick Institute; Feb 2019. Available from: www.crick. ac.uk/sites/default/files/2019-04/Crick\%20VCMFeb2019\%20 report toPost.pd

24. Worldwide Influenza Centre. Report prepared for the WHO annual consultation on the composition of influenza vaccines for the Southern Hemisphere 2019-2020. London: The Francis Crick Institute; Sep 2019. Available from: https://www.crick. ac.uk/sites/default/files/2019-10/CrickSH2019VCMreport.pdf

25. World Health Organization (WHO). Recommended composition of influenza virus vaccines for use in the 2020-2021 northern hemisphere influenza season. Geneva: WHO; Feb 2020. Available from: https://www.who.int/influenza/vaccines/virus/ recommendations/202002 recommendation.pdf?ua $=1$ 
License, supplementary material and copyright

This is an open-access article distributed under the terms of the Creative Commons Attribution (CC BY 4.0) Licence. You may share and adapt the material, but must give appropriate credit to the source, provide a link to the licence and indicate if changes were made.

Any supplementary material referenced in the article can be found in the online version.

This article is copyright of the authors or their affiliated institutions, 2020. 